\title{
Необходимость учета пространственного фактора в повышении эффективности менеджмента
}

\author{
Куприянов С.В., Денисова Е.Д., Стариков К.С. \\ Федеральное государственное бюджетное образовательное учреждение \\ высшего образования «Белгородский государственный технологический университет \\ им. В.Г. Шухова», \\ Россия, 308012, г. Белгород, ул. Костюкова, 46 \\ E-mail: kaf-mvd@yandex.ru, denisowa.eugenia2016@yandex.ru, kostariff@mail.ru
}

\begin{abstract}
Аннотация
Рассматриваются основные пути повышения эффективности менеджмента с разных точек зрения: школ управления, подходов к управлению, анализа внутренней и внешней среды. Все они имеют социальную основу происхождения и поэтому субъективны. Предлагается акцентировать внимание на выявление влияния объективных факторов, не зависящих от воли и желаний человека и, прежде всего, пространственного. Сюда относится ландшафт, климат, расположение по отношению к соседнему государству. Всё перечисленное составляет такое понятие как регион. Чтобы реализовать особенности своего пространственного положения, преимуществ и дополнительных возможностей при решении проблем, менеджмент таких регионов обязан быть ориентирован на учет специфики данного образования, обеспечивая тем самым адекватный ответ объективным и субъективным вызовам.
\end{abstract}

Ключевые слова: менеджмент, регион, пространство, эффективность, приграничная территория.

Благодарности: статья подготовлена в рамках Программы развития опорного университета на базе БГТУ имени В.Г. Шухова до 2021 года.

Для цитирования: Куприянов С.В., Денисова Е.Д., Стариков К.С. 2020. Необходимость учета пространственного фактора в повышении эффективности менеджмента. Экономика. Информатика. 47 (4): 689-699. DOI 10.18413/2687-0932-2020-47-4-689-699.

\section{The need to take into account the spatial factor in improving the effectiveness of management}

\author{
Kupriyanov S.V., Denisova E.D., Starikov K.S. \\ Federal state budgetary educational institution of higher professional education \\ «Belgorod state technological University after V.G. Shukhov», \\ 46 Kostyukova St, Belgorod, 308012, Russia \\ E-mail: kaf-mvd@yandex.ru, denisowa.eugenia2016@yandex.ru, kostariff@mail.ru
}

\begin{abstract}
The main ways to improve the effectiveness of management from different points of view are considered: management schools (scientific management, administration, human relations and behavioral Sciences, management science), management approaches (procedural, system, complex), analysis of the internal and external environment. All of them have a social origin and are therefore subjective. It is proposed to focus on identifying the influence of objective factors that do not depend on the will and desires of a person, and, above all, spatial. This includes the landscape, climate, and location relative to a neighboring state. All of the above make up such a concept as a region. In order to realize the peculiarities of their spatial position, advantages and additional opportunities in solving problems, the management of such regions must be focused on taking into account the specifics of this education, thereby ensuring an adequate response to objective and subjective
\end{abstract}


challenges. The author substantiates a system of indicators that allows assessing the level of development of border regions and allows developing a strategy for its development taking into account the location.

Keywords: management, region, space, efficiency, border area.

Acknowledgements: the article was prepared in the framework of the activities of the Development Program of the flagship university on the basis of BSTU named after V.G. Shukhov until 2021.

For citation: Kupriyanov S.V., Denisova E.D., Starikov K.S. 2020. The need to take into account the spatial factor in improving the effectiveness of management. Economics. Information technologies. 47 (4): 689-699 (in Russian). DOI 10.18413/2687-0932-2020-47-4-689-699.

\section{Введение}

Проблема повышения эффективности менеджмента вечная, не теряющая своей актуальности. С момента появления понятия эффективности в экономической науке теоретики и практики всех областей человеческой деятельности прилагали постоянные усилия, чтобы повысить результативность функционирования всех сфер приложения труда, a, следовательно, и управления ими. Приоритет отдавался, безусловно, экономике, как единству процессов производства, распределения, обмена и потребления благ и услуг, необходимых для жизни и деятельности человека. Хотя, справедливости ради, следует отметить, что проблемы менеджмента затрагивают управление армией, образованием, наукой, культурой, спортом, здравоохранением и т. д. Соответственно и занимались ими представители всех профессий: инженеры, профессиональные управленцы, социологи, психологи, математики и другие специалисты. Результат такого внимания проявился в появлении и развитии различных школ управленческой мысли. Так, школа научного управления связана с использованием в менеджменте инженерного подхода. Административная школа основывалась на теории и опыте непосредственных профессиональных управленцев. Школа человеческих отношений и поведенческих наук опиралась на достижения в области социологии, психологии, развития бихевиоризма. Школа науки управления возникла благодаря дальнейшему развитию и прикладному применению математики, разработке и адаптации математических моделей к потребностям управления, использованию количественных методов для принятия решений в сложных ситуациях.

В процессе данного исследования для решения поставленной задачи были использованы системно-холистический подход, общенаучные диалектические методы, включая анализ и синтез, метод научной абстракции, принцип рассмотрения явлений от общего к особенному и частному; количественные методы исследования, а именно, статистический метод оценки данных по отдельным показателям, характеризующим развитие Белгородской области. Кроме того, применены специальные методы экономического анализа: факторный, сравнение, группировка и др.

\section{Основные результаты исследования}

Существенным вкладом в теорию эффективности менеджмента явились исследования в области характеристики и оценки внутренней и внешней среды организации. Поскольку организация представляет собой открытую систему, то ее следует рассматривать как целостность, образованную взаимосвязанными частями, тесно переплетающимися с окружающим миром. Отличительным признаком внутренней и внешней среды является возможность влияния на них менеджмента. Внутренние переменные находятся под воздействием управленческих решений. Конечно, влияние это относительное. В то время как внешние переменные не поддаются влиянию менеджмента организации, однако их необходимо учитывать в управленческой деятельности [Демина, 2020]. 
В классическом учебнике «Основы менеджмента» [Мескон и др., 1992] к наиболее значимым внутренним переменным организации относят иели, структуру, задачи, технологию и людей. Естественно, что линейка внутренних факторов значительно длиннее, но это непринципиально. Главное, что их нельзя исследовать независимо друг от друга. К тому же необходимо учитывать, что влияние этих факторов на функцию (в данном случае эффективность) определяется уровнем развития наиболее «слабого» фактора. Здесь уместна аналогия со спортом, когда оценка эффективности команды производится по результату, показанному самым неподготовленным, слабым членом этой команды. Отсюда следует вывод, что изменения любой из приведенных переменных необходимо сопровождать адекватными изменениями остальных. В противном случае затраты на совершенствование всех внутренних факторов, оставляя неизменным хотя бы один, будут бессмысленными и безответственными [Parsons, 2010].

Вместе с тем успех деятельности организации в значительной мере определяются силами, олицетворяющими внешнее окружение, а также связью организации с миром. В специальной литературе, в зависимости от величины силы воздействия на функционирование организации, выделяется среда прямого и косвенного влияния. К среде прямого воздействия относятся: поставщчики (земли, труда, капитала), потребители, конкуренты, законы и государственные органы, профсоюзы. Среду косвенного влияния образуют: состояние экономики, социокультурные факторы, политические факторы, научно-технический прогресс, международные события.

Приведенный набор факторов, который необходимо учитывать для эффективного менеджмента, свидетельствует об их разнообразии, разновекторности, измеримости, качественности, возможности учета и прочими расхождениями. Однако общее у них то, что они все имеют социальную природу происхождения. Все они являются порождением человека, результатом человеческого сознания, труда, стремлений, а, следовательно, субъективны по своей природе. Их следует изучать, исследовать, измерять степень влияния на эффективность менеджмента, но необходимо также обратить внимание на объективные факторы, не зависящие от воли и желания человека. К таким факторам, прежде всего, относится Природа. Поскольку это очень емкое понятие - всё, что нас окружает, за исключением созданных человеком творений - то ограничимся рассмотрением той ее части, которая в наибольшей степени связана с экономикой - географической среды. Зависимость человека от Природы не оспаривалась никогда и никем, хотя степень этой зависимости расценивалась различными учеными не одинаково. Но в любом случае хозяйственная жизнь народов, населяющих и населявших Землю, тесно связана с ландшафтами и климатом населенных территорий. В свою очередь ландшафт и климат являются составляющими такого современного понятия как регион и его роли в экономическом развитии [Гумилев, 1990].

Термин «регион» был введен в России академиком Н.Н. Некрасовым в 1975 году. Академик предложил рассматривать регион как «... крупная территория страны с более или менее однородными природными условиями, а главным образом характерной направленностью развития производительных сил на основе сочетания комплекса природных ресурсов с соответствующей сложившейся и перспективной социальной инфраструктурой». Основным критерием, позволяющим выделить регион, является «общность народнохозяйственных задач, основанных на совокупности используемых или намечаемых к эксплуатации природных богатств, исторически сложившейся структуре хозяйственной деятельности или плановой структуре экономического развития». В качестве регионов Н.Н. Некрасов выделял союзные республики и экономические районы СССР, а также районы размещения отраслей промышленности, сельского хозяйства и транспорта [Некрасов, 1978].

Существует достаточно много определений региона в разных областях человеческого знания, каждое из которых характеризует какую-либо сторону этого термина. Так, в научной литературе можно выделить следующие подходы к толкованию термина «регион». Географический (месторасположение, размеры территории и количество населения, 
климатические условия); производственно-функциональный (специализация территории в определенном виде деятельности); градостроительный (особенности застройки объектов производственной и хозяйственной деятельности, жилых кварталов, обслуживания населения); социальный (этические и моральные нормы общения, культуры, поведение населения); административный (административно-территориальное деление). Из них только географический подход обладает, на наш взгляд, наиболее объективными характеристиками. Все остальные - более субъективные определения, но тем не менее подверженные влиянию объективного фактора.

Наряду с понятием «регион» в практике тематических исследований часто используется термин «район», выступающий синонимом рассматриваемого понятия. Так, Э.Б. Алаев определяет район как «локализованную территорию, обладающую единством, взаимосвязанностью составляющих элементов, целостностью, причем эта целостность объективное условие и закономерный результат развития данной территории» [Алаев, 1983].

Географическая среда влияет на организмы, в том числе и людские. Этот вывод сделал в 1922 г. Л.С. Берг: «Географический ландшафт воздействует на организм принудительно, заставляя все особи варьировать в определенном направлении, насколько это допускает организация вида. Тундра, лес, степь, пустыня, горы, водная среда, жизнь на островах и т. д. все это накладывает особый отпечаток на организмы. Те виды, которые не в состоянии приспособиться, должны переселиться в другой географический ландшафт или вымереть» [Берг, 1922]. А под ландшафтом понимается «...территориальный комплекс, в пределах которого основные ландшафтные компоненты, которые его составляют (земная кора, вода, климат, растительность и животный мир), образуют взаимосвязанное и взаимообусловленное единство» [Понятие ландшафта.., 2020].

В отечественной литературе также широко представлены трактовки понятия «регион» других исследователей, основанные на территориальном, географическом, экономическом и иных признаках, в частности, регион - это:

- «территориально-специализированная часть народного хозяйства страны, характеризующаяся единством и целостностью воспроизводственного процесса» [Добрынин, 1977];

- «субъект РФ, административно-территориальное образование и даже город» [Лексин, Швецов, 1993];

- «подсистема социально-экономического комплекса страны, а также относительно самостоятельная его часть с законченным циклом воспроизводства и специфическими особенностями протекания социальных и экономических процессов» [Основы теории, 1998];

- и др.

В Указе Президента Российской Федерации «Об утверждении основ государственной политики регионального развития Российской Федерации на период до 2025 года» от 16 января 2017 года № 13, регион определяется как «часть территории Российской Федерации в границах территории субъекта Российской Федерации» [Указ Президента РФ, 2017].

Традиционно исследования, связанные с пространственным развитием приграничных территорий, имели экономическую перспективу. Нильс Хансен тщательно изучил теорию местоположения и литературу о полюсах роста, связанную с пограничными регионами. Он пришел к выводу, что в литературе подчеркивается хрупкая и опасная природа пограничных регионов, но тем не менее стабильная граница может также иметь преимущества для экономики соседних регионов [Hansen, N., 1977].

Ратти Р. выделил два различных подхода к экономическому развитию приграничных регионов, которые применялись в большинстве исследований, посвященных пространственному влиянию границ на региональное развитие. Первый подход изучает пограничные районы как территории, близкие к институциональным границам, и нацеливает их на воздействие, которое границы оказывают на экономическую и социальную жизнь. Во 
втором случае границы рассматриваются как внешние ограничения и препятствия для коммуникации [Ratti, R. 1994.].

Региональные науки и пространственный анализ часто имеют сильную политическую ориентацию. Эти исследования направлены на получение данных, которые помогают региональным властям и бизнес-структурам разрабатывать различные стратегии.

Таким образом, не менее важное влияние на развитие экономики хозяйствующего субъекта (объединения, фирмы, региона, субъекта Федерации и др.) а, следовательно, и его менеджмента, имеет пространственное расположение и в отношении других соседних государств. Находится ли данный субъект в центральной части страны или на ее окраине? Кто соседи? Каковы отношения с ними? и т. д. Поэтому в каждом конкретном случае должна быть определена структура экономики данного хозяйствующего субъекта, которая при всей непохожести на организацию хозяйства другого приграничного района в силу природногеографических условий должна соответствовать определенным требованиям. В частности, активная часть основных фондов отличатся высокой степенью мобильности, позволяющей их эвакуировать в более безопасные районы. Кроме того, экономике приграничного региона присущ высокий уровень автономии, поскольку в случае ее разрушения, частичного или полного, экономика государства в целом должна пострадать минимально и не потерять своей устойчивости от возможного разбалансирования. Это как на подводной лодке, когда пострадал один отсек, его изолируют, а лодка продолжает функционировать в штатном режиме. Определенные требования предъявляются и к населению приграничного региона. Прежде всего, по плотности расселения, возрастной структуре. Особое место, на наш взгляд, отводится наличию здесь субкультуры - устойчивой организованной формы культуры со своими специфическими традициями, ценностями, устоями, которая существует наряду с традиционной обычной культурой [Словарь по культурологии, 2020].

На территории приграничных регионов не должны создаваться стратегические объекты военно-промышленного комплекса, предприятия, обеспечивающие национальную безопасность, но размещены объекты, позволяющие проведение оборонительно-наступающих операций. Данное обстоятельство, естественно, определяет особенность формирования в том числе и экономического развития приграничной территории. Однако бизнес, предпринимательство развивается по своим законам, которые предполагают, что ограничения в одном направлении развития компенсируются свободой в другом, что чем больше рисков, тем выше норма прибыли. И для всего этого должны быть созданы и обеспечены соответствующим правовым полем необходимые условия льготного функционирования хозяйственных структур.

Для того чтобы реализовать особенности своего местоположения, преимуществ и решения проблем, менеджмент таких регионов обязан быть ориентирован на учет специфики данного образования, обеспечивая тем самым адекватный ответ объективным и субъективным вызовам.

Одной из самых сложных задач, стоящих перед правительствами приграничных регионов в области межгосударственных отношений, является нахождение баланса между конкурирующими и, казалось бы, противоречивыми приоритетами. Особенно это касается мобильности и безопасности, интересы пересекаются. С одной стороны, приграничность региона открывает большой потенциал для содействия экономическому росту и развитию, инновациям, через опыт и взаимодействие с приграничным государством. С другой стороны, власти должны обеспечить национальную безопасность, происходит постоянная борьба с транснациональной преступностью (торговля людьми, контрабанда и терроризм и др.), что влечет дополнительные расходы из бюджета.

В то же время каждая граница уникальна и единого универсального решения быть не может, существуют общие черты и опыт разных стран, что может быть учтено в национальном подходе к управлению границами. Управление и коммуникации, которые позволяют осуществлять взаимодействие и координацию между различными межведомственными 
организациями, эффективны только в том случае, если должным образом включены в планируемую оперативную деятельность.

В последние годы политику и практику управления границами в современных быстро меняющихся условиях можно охарактеризовать как «реактивную», поскольку Правительство изо всех сил пытается как можно быстрее реагировать на происходящие события, возникающие угрозы и т. д.

И подобные требования будут только возрастать по мере усиления процессов глобализации, и в связи с этим появления новых видов угроз для отдельных государств. Пограничные организации должны быть гибкими, если они хотят обеспечить эффективную и устойчивую защиту от этих угроз.

Подтверждение приведенных теоретических рассуждений попытаемся сделать на основе анализа конкретных показателей развития одного из субъектов Российской Федерации. В качестве объекта исследования берем Белгородскую область. Сразу оговоримся, что Белгородская область по целому ряду социально-экономических показателей, по духовнонравственному развитию населения занимает ведущее положение среди аналогичных субъектов Федерации.

Так, характер отраслевого развития в определенной мере отражают показатели, приведенные в табл. 1.

Таблица 1

Table 1

Динамика отдельных показателей по Белгородской области, характеризующих позитивные тенденции развития региона

Dynamics of individual indicators for the Belgorod region that characterize positive trends in the region's development

\begin{tabular}{|l|c|c|c|c|c|}
\hline \multicolumn{1}{|c|}{ Показатели } & 2014 & 2015 & 2016 & 2017 & 2018 \\
\hline $\begin{array}{l}\text { Среднедушевые денежные доходы } \\
\text { населения (в месяц), руб. }\end{array}$ & 25371,5 & 28331,5 & 29590,7 & 30219,0 & 30759,8 \\
\hline $\begin{array}{l}\text { Валовой региональный продукт на } \\
\text { душу населения, руб. }\end{array}$ & 400821 & 447630 & 469922 & 506421 & - \\
\hline $\begin{array}{l}\text { Ввод в действие основных фондов, } \\
\text { млн руб. }\end{array}$ & 101835 & 88118 & 128775 & 140488 & - \\
\hline $\begin{array}{l}\text { Продукция сельского хозяйства, } \\
\text { млн руб. }\end{array}$ & 188217,3 & 220692,1 & 226056,3 & 227267,4 & 245147,1 \\
\hline $\begin{array}{l}\text { Добыча металлических руд, млн } \\
\text { руб. }\end{array}$ & 84222,7 & 81211,1 & 88929,9 & 113394,7 & 145098,2 \\
\hline $\begin{array}{l}\text { Инвестиции в основной капитал, } \\
\text { направленные на охрану } \\
\text { окружаюей среды и рациональное } \\
\text { использование природных ресурсов, } \\
\text { млн руб. }\end{array}$ & 1201,7 & 2134,5 & 922,2 & 996,3 & 1631,7 \\
\hline Объем услуг связи всего, млн руб. & 11860,5 & 11921,3 & 13016,9 & 13266,4 & 13547,4 \\
\hline $\begin{array}{l}\text { Производство основных продуктов } \\
\text { животноводства за один день: } \\
\text {-молока, тонн } \\
\text {-яйца, тыс. шт. }\end{array}$ & \begin{tabular}{l}
1491 \\
\hline
\end{tabular} & $\begin{array}{l}1456 \\
4048\end{array}$ & $\begin{array}{l}1482 \\
4331\end{array}$ & $\begin{array}{l}1626 \\
4554\end{array}$ & $\begin{array}{l}1709 \\
4542\end{array}$ \\
\hline
\end{tabular}

Источник: составлено авторами по материалам [Белгородская область в цифрах..., 2019; Департамент экономического...,2020] 
Анализ приведенных в табл. 1 данных позволяет утверждать, что хозяйственный комплекс области имеет устойчивый тренд во многих отраслях, определяющих место области в национальном разделении труда. Необходимо также учитывать, что для анализа выбран период, характерный тем, что все происходит в условиях нарастающих как снежный ком экономических санкций со стороны США и высокоразвитых стран Европейского Союза. Вместе с тем нельзя и отрицать, что устойчивое состояние обеспечивается достижениями, прежде всего, отраслевого развития. Отраслевое планирование занимает ведущее положение и показывает высокие результаты. Это хорошо. Но проблема в том, что получаемая продукция, полученная на отраслевых предприятиях, как правило, не является конечным продуктом, то есть продуктом, предназначенным для конечного использования, а не полуфабрикатом для дальнейшей переработки. Интересам человека такое производство, несомненно, соответствует, но не прямо, а опосредовано, косвенно [Денисова, 2018].

В этой связи достаточно любопытны данные, приведенные в табл. 2.

Таблица 2

Table 2

Динамика отдельных показателей развития Белгородской области, характеризующих социальные проблемы развития региона

Dynamics of individual indicators of development of the Belgorod region that characterize the social problems of the region's development

\begin{tabular}{|c|c|c|c|c|c|}
\hline Показатели & 2014 & 2015 & 2016 & 2017 & 2018 \\
\hline $\begin{array}{l}\text { Естественный прирост, убыль } \\
\text { (-) населения на } 1000 \text { чел. } \\
\text { населения }\end{array}$ & $-2,5$ & $-2,4$ & $-2,8$ & $-3,8$ & $-4,3$ \\
\hline $\begin{array}{l}\text { Миграционный прирост, } \\
\text { убыль (-) населения на } 1000 \\
\text { чел. }\end{array}$ & 4,9 & 3,8 & 4,5 & 1,8 & 2,7 \\
\hline $\begin{array}{l}\text { Население в возрасте: } \\
\text { - трудоспособном } \\
\text { - старше трудоспособного }\end{array}$ & $\begin{array}{l}- \\
-\end{array}$ & $\begin{array}{l}896493 \\
403684\end{array}$ & $\begin{array}{l}882974 \\
413412\end{array}$ & $\begin{array}{l}872415 \\
421963\end{array}$ & $\begin{array}{l}859308 \\
429399\end{array}$ \\
\hline $\begin{array}{l}\text { Ввод в действие общей } \\
\text { площади жилых домов, } \\
\text { тыс. кв. м. }\end{array}$ & 1469,2 & 1554,9 & 1350,1 & 1300,4 & 1215,5 \\
\hline Браки/разводы на 1000 чел & $8,5 / 5,0$ & $8,3 / 4,4$ & $6,1 / 4,4$ & $7,3 / 4,4$ & $6,7 / 4,4$ \\
\hline $\begin{array}{l}\text { Число родившихся и умерших } \\
\text { на } 1000 \text { чел. }\end{array}$ & $11,5 / 14,0$ & $11,5 / 13,9$ & $11,1 / 13,9$ & $9,7 / 13,5$ & - \\
\hline $\begin{array}{l}\text { Число больничных коек на } \\
10000 \text { чел. населения }\end{array}$ & 80,4 & 77,1 & 72,7 & 73,0 & 72,2 \\
\hline Численность врачей, чел & 6307 & 6400 & 6457 & 6365 & 6263 \\
\hline $\begin{array}{l}\text { Численность среднего } \\
\text { медицинского персонала, чел. }\end{array}$ & 17467 & 17575 & 17474 & 16963 & 16555 \\
\hline
\end{tabular}

Источник: составлено авторами по материалам [Белгородская область в цифрах..., 2019; Департамент экономического...,2020]

Все показатели табл. 2 «замыкаются» на человеке, его интересах, вкусах, предпочтениях, моральном состоянии, уверенности в завтрашнем дне, здоровье, настроении и т. п., что определяет качество жизни. Но это уже главная проблема пространственного развития данного региона, забота территориального планирования.

Оценка тенденции показателей с 2014 по 2018 годы в табл. 2 свидетельствует о не совсем благоприятном состоянии в тренде Белгородской области. Решение выявленных проблем - повышения уровня жизни населения области - требует принципиальных изменений в стратегии ее развития и, прежде всего, в отношении определения приоритетов отраслевого или территориального планирования. А учитывая ее пространственное расположение, 
приграничный характер, допускается, что акцент следует сделать на более интенсивное развитие «человекообслуживающей» инфраструктуры и с этой целью необходимо откорректировать стратегию развития этого уникального во многих отношениях региона [Куприянов и др., 2018].

Учет пространственного фактора в стратегии приграничных регионов предполагает соблюдение определенных принципов их развития. В частности, уровень жизни населения этих регионов должен быть не ниже среднего уровня по стране. Обеспечить это возможно только на основе приоритета территориального (регионального) планирования над отраслевым. Каждый из этих видов планирования призван решать разные задачи. Если приоритетом отраслевых хозяйствующих субъектов являются показатели, характеризующие их деятельность в натуральном и стоимостном выражении, то территориальные органы управления должны, прежде всего, отвечать за качество жизни проживающего на данной территории населения. В первом случае это может быть километры построенных дорог, кв. метров введенных зданий и сооружений, тонн добытой руды, произведенного разного вида мяса, выращенной сельскохозяйственной продукции, количество койко-мест в больницах, количество обучающихся в высших и средних учебных заведений и т. д. и т. п. Во втором случае общее количество оценивающих показателей может быть существенно меньше, поскольку они отражают конечные показатели качества жизни: средняя продолжительность жизни, соотношение рождаемости и смертности, браков и разводов, направление миграционных потоков. Конечно, линейку оценивающих показателей первой и второй группы можно значительно расширить, но суть при этом не изменится. Главное то, что, хотя они в известной мере определяют друг друга, но они не взаимозаменяемые [Куприянов, Трошин, 2018].

Современный регион - это та система, которая постоянно подвержена различным потрясениям, таким как рецессия, технологические прорывы, политические изменения и т. п. Данные потрясения оказывают дестабилизирующее влияние на процесс и структуру экономического развития региона, они в наибольшей степени оказывают влияние именно на региональные (городские, областные и пр.) социально-экономические системы. Наряду с глобальными или национальными изменениями, существуют также потрясения, возникающие на местном уровне и обусловленные местными особенностями, например, ликвидация или перемещение основного работодателя, локальное закрытие отрасли и пр. Следовательно, логично предположить, что пространственный фактор имеет большое значение в эффективности менеджмента территориальных образований и исследовании реакций регионов на различные потрясения, а также в изучении процесса восстановления после данных потрясений, и, как следствие, для понимания роли, которую такие потрясения могут играть в области пространственной динамики социально-экономического развития региона.

\section{Заключение}

Таким образом, на основании вышеизложенного материала можно сделать следующие выводы:

- проблемы повышения эффективности менеджмента являются «вечной» темой теоретиков и практиков, занимающихся вопросами управления. Поиском путей достижения успехов были заняты представители различных школ и подходов исследований в области менеджмента;

- характеристика и анализ элементов внутренней и внешней среды организаций свидетельствует об их субъективной природе. Все они являются результатом человеческой деятельности, независимо от того может или нет менеджмент данной организации повлиять на них или принять как должное;

- недостаточное внимание уделяется повышению эффективности менеджмента за счет регионального фактора. Региональную составляющую формирует такой элемент как ландшафт, объективно воздействующий на человека и принудительно заставляющий 
организовывать его, в том числе и хозяйственную деятельность с учетом требований географической среды;

- любой подход, разработанный для управления приграничными регионами, должен объединить безопасность и коммерцию в единую систему, которая поддерживает национальные приоритеты страны, а также политические, экономические, социальные и культурные потребности населения. Строительство «непробиваемой стены» нарушило бы баланс между безопасностью и коммерцией;

- создание всеобъемлющего потенциала управления границами вытекает непосредственно из основ, принципов и уроков, извлеченных из опыта других стран в попытке развивать пограничные системы 21-го века. Эти извлеченные уроки представлены в виде руководств и рекомендаций, идей, а не как директивы, и должны быть адаптированы для достижения конкретных стратегических и оперативных национальных целей;

- анализ современной практики хозяйствования (на примере одного из субъектов Федерации - Белгородской области) показывает, что достижение высоких рейтингов региона обеспечивается, в основном, уровнем отраслевого его развития. Территориальное управление в силу ряда причин исторического, традиционного, инвестиционного, инерционного и прочего характера занимает по отношению к отраслевому ведомую позицию;

- пространственное расположение региона относительно соседних государств, приграничных регионов предъявляет ряд требований к организации его экономической, культурной, демографической, социальной, внешней и правовой политики, бизнеса. Региональная политика обязана ориентироваться и адекватно реагировать на вызовы своего месторасположения.

\section{Список литературы}

1. Алаев Э.Б. 1983. Социально-экономическая география: понятийно-терминологический словарь. М., Мысль, 350.

2. Белгородская область в цифрах. 2019. Белгородстат, 252.

3. Берг Л.С. 1922. Номогенез. Пг., 181.

4. Гумилев Л.Н. 1990. Этногенез и биосфера Земли. Л., Гидрометеоиздат, 528.

5. Демина Н.В. Стратегия как ведущий элемент стратегического менеджмента: понятие, сущность и основные характеристики [Электронный ресурc]. URL: http://pglu.ru/upload/iblock/c60/ uch_2008_xii_00034.pdf (дата обращения: 02.02.2020 г.)

6. Денисова Е.Д. 2018. Анализ и оценка социально-экономического развития Белгородской области. Пространственное развитие территорий: сборник научных трудов международной науч.практ. конф. Белгород, ООО «ЭПИЦЕНТР»: 350-354.

7. Департамент экономического развития Белгородской области URL: https://belregion.ru/documents/region_programms.php (дата обращения: 15.03.2020).

8. Добрынин, А.И. 1977. Региональные пропорции воспроизводства. Ленинград, Изд-во Ленингр. ун-та, 127.

9. Куприянов С.В., Стрябкова Е.А., Герасимова Н.А. 2018. Особенности экономического развития приграничных регионов. Научные ведомости Белгородского государственного университета. Экономика Информатика, 45-1: 5-14.

10. Куприянов С.В., Трошин А.С. 2018. Необходимость системного и комплексного исследования развития приграничных территорий. Пространственное развитие территорий: сборник научных трудов международной науч.-практ. конф. Белгород, ООО «ЭПИЦЕНТР»: 20-25.

11. Лексин, В.Я, Швецов А.Н. 1993. Региональные бюджетно-налоговые системы. Российский экономический журнал, 12: 77-83.

12. Мескон М.Х., Альберт М., Хедоури Ф. 1992. Основы менеджмента. М., «Дело», 702.

13. Некрасов Н.Н. 1978. Региональная экономика. Теория, проблемы, методы. М., Экономика,

344.

14. Основы теории регионального воспроизводства: курс лекций. 1998. М., Экономика, 191.

15. Понятие ландшафта. Типы ландшафта. Ландшафтный анализ объекта. Megaobuchalka.ru URL: https://megaobuchalka.ru/7/43137.html (дата обращения: 03.03.2020). 
16. Словарь по культурологии. Studfiles.net URL: https://studfiles.net/preview/1865391/page:2/. (дата обращения: 10.02.2020)

17. Указ Президента РФ от 16 января 2017 года № 13 «Об утверждении Основ государственной политики регионального развития Российской Федерации на период до 2025 года».

18. Hansen, N. 1977. Border Regions: a Critique of Spatial Theory and a European Case Study. Annals of Regional Science, 11(1): 1-14.

19. Parsons D. 2010. Organisational resilience. The Australian Journal of Emergency Management, 25 (2): $18-20$.

20. Ratti, R. 1994. Spatial Effects of Frontiers: Overview of Different Approaches and Theoriesof Border Region Development. In P. Nijkamp (ed.), New Borders and Old Barriers in Spatial Development: 15-33.

\section{References}

1. Alaev E.B. 1983. Socio-economic geography: a conceptual and terminological dictionary. Moscow, Mysl, 350.

2. Belgorod region in numbers. 2019: Krat. stat. SB. Belgorodska, 252.

3. Berg L S. 1922. Nomogenesis. PG. P.:180-181.

4. Gumilev L.N. 1990. Ethnogenesis and biosphere of the Earth. L., Hydrometeoizdat, 528.

5. Demina N.V. Strategy as a leading element of strategic management: concept, essence and main characteristics [Electronic resource]. URL: <url> http://pglu.ru/upload/iblock/c60/uch_2008_xii_00034.pdf (accessed: 02.02.2020)

6. Denisova E.D. 2018. Analysis and assessment of socio-economic development of the Belgorod region. Spatial development of territories: collection of scientific works of international scientific practice. Conf. Belgorod, LLC "EPICENTER": 350-354.

7. Department of economic development of the Belgorod region. URL: https://belregion.ru/documents/region_programms.php (accessed: 15.03.2020).

8. Dobrynin, A.I. 1977. Regional proportions of reproduction. and secondary special education of the RSFSR. Leningrad, Leningr Publishing house, UN-TA, 127.

9. Kupriyanov S.V., Stryabkova E.A., Gerasimova N.A. 2018. Features of economic development of border regions Scientific Bulletin of the Belgorod state University Economics Informatics, 45-1: 5-14.

10. Kupriyanov S.V., Troshin A.S. 2018. The need for a systematic and comprehensive study of the development of border territories. Spatial development of territories: collection of scientific works of international scientific practice. Conf. Belgorod, LLC "EPICENTER": 20-25.

11. Leksin, V.Ya, Shvetsov A.N. 1993. Regional budget and tax systems. Russian economic journal, 12: 77-83.

12. Mescon M.H., Albert M., Hedouri F. 1992. Fundamentals of management: TRANS. from English-M., "Delo": 702.

13. Nekrasov N.N. 1978. Regional economy. Theory, problems, methods. Moscow, Ekonomika: 344.

14. Fundamentals of the theory of regional reproduction: a course of lectures. 1998. Moscow, Ekonomika: 191.

15. The concept of landscape. Type of landscape. Landscape analysis of an object. URL: 5 . https://megaobuchalka.ru/7/43137.html (accessed: 03.03.2020). 10.02.2020)

16. Dictionary of cultural studies. URL: https://studfiles.net/preview/1865391/page:2/. (accessed:

17. Decree of the President of the Russian Federation No. 13 of January 16, 2017 "on approval of the state policy Of regional development of the Russian Federation for the period up to 2025".

18. Hansen, N. 1977. Border regions: criticism of spatial theory and European case study. Annals of regional science, $11(1)$ : 1-14. (2): $18-20$.

19. Parsons D. 2010. Organizational stability. The Australian Journal of Emergency Management, 25

20. Ratti, R. 1994. Spatial effects of borders: an overview of various approaches and theories of development of border regions. In P. Nijkamp (ed.), New borders and old barriers in spatial development: 15-33. 


\section{ИНФОРМАЦИЯ ОБ АВТОРАХ}

Денисова Евгения Дмитриевна, ассистент кафедры менеджмента и внешнеэкономической деятельности БГТУ им. В.Г. Шухова, Белгород, Россия

Куприянов Сергей Васильевич, доктор экономических наук, профессор, профессор кафедры менеджмента и внешнеэкономической деятельности БГТУ им. В.Г. Шухова, Белгород, Россия

Стариков Константин Сергеевич, аспирант кафедры менеджмента и внешнеэкономической деятельности БГТУ им. В.Г. Шухова, Белгород, Россия

\section{INFORMATION ABOUT THE AUTHORS}

Evgeniya D. Denisova, Assistant of the Department of Management and Foreign Economic Activity of BSTU named after V. G. Shukhov, Belgorod, Russia

Sergey V. Kupriyanov, Doctor of Economics, Professor, Professor of the Department of Management and Foreign Economic Activity of BSTU named after V. G. Shukhov, Belgorod, Russia

Konstantin S. Starikov, Post-graduate Student of the Department of Management and Foreign Economic Activity of BSTU named after V.G. Shukhov, Belgorod, Russia 